\title{
The wonderful thing about tiggers
}

\section{Tara Woodyer}

Department of Geography, University of Portsmouth, Buckingham Building, Lion Terrace, Portsmouth, PO1 3HE

Email: tara.woodyer@port.ac.uk

\section{The wonderful thing about tiggers}

Is tiggers are wonderful things!... ${ }^{1}$

I was given my first Winnie-the-Pooh plush toy for my seventeenth birthday. He spoke and wriggled his nose when you squeezed him, and I used to put his nose to mine in an eskimo kiss $^{2}$. This was the start of an obsession with A.A Milne's Hundred Acre Wood characters that quickly came to focus on Tigger; a tiger - although neither Tigger or his friends ever refer to him as such - known for his springy tail and love of bouncing. I can't remember what prompted the request for that plush toy, but Tigger and his friends quickly came to dominate my childhood bedroom (plush toys, books, videos, prints), the wider family home (mugs, ornaments), my mum's crafting hobbies (rug making, embroidery), and my friendships. Whilst I was Tigger, my best friend was Piglet, and we swapped Winnie-the-Pooh gifts; at our joint $18^{\text {th }}$ birthday party I had a Tigger cake, she had a Piglet one. Tigger spoke to a key aspect of my personality at that age, bounciness: an incessant playful attitude and not taking yourself too seriously. In reality, I was very shy, but was able to hide this well with this outgoing persona. I actively styled myself as the 'bounce-meister'3 and my oversized plush Tigger was there to comfort me at the times when I didn't feel quite so bouncy for whatever reason, because even Tigger's can have off days. 
[Image of big Tigger] Plush Tigger at the family home

When I left home to start out on my academic career, the vast majority of my Winnie-thePooh paraphernalia stayed at the family home due to storage restraints, but Tigger's spirit stayed with me. As my intellectual interests and research came to focus on children's geographies I actively sought to cultivate a playful identity. In practice, it didn't feel like cultivating, it came naturally, but I felt the need to construct an intellectual rationale about it - centred on the 'need' for it in my child-focused research - to justify acting differently as an academic (see Gillan and Pickerill 2012 on issues of identity within the neoliberal university system; for a broader discussion of the relation between play and work see Woodyer 2012). This involved developing a methodology incorporating observant participation, playing with children and their toys in their family home (see Woodyer 2008). Having a range of toys in my office - some from my own childhood, such as Sylvanian Families figures; others from the lifewords of the children I was working with, such as Bratz dolls - was, at once, part of this positioning of myself as a 'playful' academic figure, and signalling that this 'stuff' of childhood mattered within academia ${ }^{4}$. It was an attempt, and a call for others, to be 'serious about the frivolous and frivolous about the serious' (Dibbell 1991, n.p, cited in Cook and Woodyer 2012).

It's at this point that I met Hilary Geoghegan and was introduced to her wonderfully insightful research on enthusiasm. Our firm friendship became cemented when, bored of yet another depressingly downbeat critical reflection on such and such a topic, we left a seminar early and headed to the pub. Consumed by the shared sentiment that there must be another way of doing things - 'a less repressed, more cheerful way of engaging with the geographies 
of the world' (Woodyer and Geoghegan 2013) - we sketched out the idea for a conference session on Enchanting Geographies on the back of a beer mat. This set us on the path to a series of articles on (re)enchanting geography, that seek 'to question the accepted rules for thinking and acting in human geography, making space for ways of being, doing and writing that are less to do with rationality and/or reason' (Woodyer and Geoghegan 2013: 210). Drawing on our interests in play and enthusiasm, these papers ${ }^{5}$ seek to make space for an ethic akin to the one John calls for in his essay (see also Geoghegan and Woodyer 2014). We acknowledge in the papers that attempting to carve out such a space is a bold move (and the reviewers were clear we had to anticipate and respond to the likely ripostes). Yet, '[i]t was a move we had to make as we registered our growing disillusion with not only the practices of a discipline about which we are passionate, but also its ability to address and have lasting impact upon the pressing concerns of our time' (Woodyer and Geoghegan 2013: 210).

Around the same time as writing my first paper with Hilary, I was exploring these ideas in a more empirical way in my commodity-based work with Ian Cook. Bringing together our experiences of being a student and a teacher of commodity geographies (which explicitly wove together my own engagements with material and popular culture with those of my child research participants), we argued for an 'affective geography, at once ludic, imaginative, and politically informed' (Cook and Woodyer 2012: 238). This played on the fact that 'each individual is a complex, de-centred subject with multiple modalities of consciousness operating at different times, in different places, and in different capacities' (Cook and Woodyer 2012: 238), which is perhaps a useful line of enquiry for engagements with how our own childhood is inflected in our research. 
There's an important and curious thread that links these two strands of work - (re)enchanting geography and commodity geographies - beyond their shared conceptual and philosophical standpoints. They were both situated outside of the sub-disciplinary space of children's geographies. Given broader moves within the discipline to call for something akin to, or at least not in tension with, a playful ethic, it is peculiar that this hasn't been explored more readily within children's geographies, the very sub-disciplinary space where one might expect to find an engagement with playfulness.

Or is it? John's essay documents three provocative silences arising from Chris's wonderful lecture, but in that lecture room at the RGS-IBG conference listening to Chris speak, I was consumed by a different silence. Sitting in an intellectually rich and (despite John's worries) collegiate space, I couldn't help but reflect on how I had expended so much energy across my career to date on 'branding' myself as something other (and dare I say 'something more') than a children's geographer. As uncomfortable as this is to air out loud in print, it might be worth reflection beyond my own personal concerns.

At a time when the sub-discipline has celebrated its coming of age (Matthews 2003; Philo 2016), I've been frustrated by the strive for legitimacy and credibility within my own childand play-focused research. I started my PhD two years after the journal had seen its first issue published. My responses to the dreaded question, "So what's your research on?" where typically met with a tilt of the head, "Oh, that's nice", change of topic scenario. At best, I would be offered an anecdote about one's own childhood play, or the play of a younger family member. On the one hand, I appreciated the fact that seemingly anyone could engage with my research on this most basic of levels, on the other, I longed for some form of critical discussion. For this reason, I took to describing myself as a cultural geographer with an 
interest in embodied practice and materiality, which just happened to involve research with children, toys and play. This strive for credibility later saw me actively turn my interest in children, toys and play to the 'bigger', seemingly more legitimate topic of war and conflict, using military action figures as a lens through which to explore children's enactment of geopolitics. Perhaps, this speaks to nothing more than a personal sense of insecurity, but at the same time, others were turning their more cheerfully inflected interests to 'harder' issues such as climate change (Geoghegan and Leyshon 2012). Perhaps this was part of our personal coming of age within academia, a rite of passage. We were now at a career stage where we had a permanent position, where we were taking on leadership roles, where we were being asked to think about promotion...

\section{Mostly I'm happy and I'm bouncy}

\section{Because I am the onliest one...}

\section{...Right now I'm sorta feelin' downcy}

\section{I'm just about the loneliest one ${ }^{6}$}

And here I return to Tigger. Hilary and I noted in our writing that we weren't expecting human geographers to be enchanted (read: cheerful) all of the time. Whilst an assortment of action figures still furnished my office, the Tigger had been knocked out of me. The playfulness was gone. I began distributing my plush Winnie-the-Pooh toys to friends' young children, the Winnie-the-Pooh mugs at my mum's house were boxed and earmarked for a car boot sale. Whilst I was thoroughly enjoying my research sessions with my child participants as part of our Ludic Geopolitics project, I felt lost intellectually. This was certainly not helped by an ever-incessant institutional attention to metrics, questions about where I would publish and who the likely readership would be (and autocorrect functions on various devices 
changing the word 'ludic' to ludicrous') (see Mountz et al 2015). I'm necessarily distilling a very complex issue down to a few crude elements, but when I paused to reflect on how I'd ended up where I was at that point, one figure offered a ray of hope. Tigger. He reminded me that it's okay to feel lost ${ }^{7}$. He reminded me of who I had been. He showed me who I could be again. He held out a hand to help me recover a sense of integrity...

I join John in encouraging more geographers to try to cultivate an ethic of playfulness (and hope my story doesn't dampen their enthusiasm for this), but would also welcome a space for reflection on issues around credibility if we are to take this move seriously and better support it as a community. In calling for more playfulness, we also have to think carefully about what we mean by this, avoid the trap of falling into romanticised notions of play and a totalising vitalism where everything is exciting and lively all of the time, and remember the various forms that play can take, including dark play (see endnote 4 as an albeit light-hearted example). As children's geographers (yes, I am one, and say this proudly now) we should be 'serious about the frivolous and frivolous about the serious', but we also need to realise that is a refined art (Cook and Woodyer 2012: 238). We need to be more open about the various resources needed to develop and support it.

[Image of Tigger mug] Tigger proudly back in my office.

\section{Acknowledgements}

Thanks to John Horton for providing his thought provoking commentary, to Tracey Skelton for inviting me to provide a response, and to Hilary Geoghegan for comments on an early draft and for agreeing I could reference her in this personally reflective piece.

\section{Notes}


${ }^{1}$ Lyrics from 'The Wonderful Thing about Tiggers', Tigger's theme tune. Music and lyrics by Richard M. Sherman and Robert B. Sherman, The Tigger Movie Soundtrack (2000).

${ }^{2}$ An Eskimo kiss in modern Western culture is the act of pressing the tip of one's nose against another's. It is loosely based on a traditional Inuit greeting called a kunik.

${ }^{3}$ Tigger is often described as the original bouncemeister on merchandise.

${ }^{4}$ My office mates played upon this. One day I came into the building to find police tape around the office door. This marked the area of a crime scene. They had used my toys and various other objects to hand, including a cutlery knife, to construct the Toy Town Massacre scene, complete with blood and gore (red blobs coloured in felt-tipped pens). This is but one example of how these toys brought much needed light relief to their academic endeavours involving peat bogs, varves, marine tephra and pollen.

${ }^{5}$ I'd like to take this opportunity to again thank Chris Philo in his encouragement and helpful suggestions for this writing in his role as journal editor.

${ }^{6}$ Lyrics from 'Someone Like Me' sung by Tigger in The Tigger Movie. Music and lyrics by Richard M. Sherman and Robert B. Sherman, The Tigger Movie Soundtrack (2000).

${ }^{7}$ The Tigger Movie plotline involves Tigger searching for his family when he realises that his friends are not quite as bouncy as he is because they are not Tiggers, and he finds himself feeling lost and lonely.

\section{References}

Cook, I. \& Woodyer, T. 2012. The Lives of Things. In The Wiley-Blackwell Companion to Economic Geography, edited by T.J. Barnes, J. Peck, J. \& E. Sheppard, 226-239. Oxford: Blackwell. 
Dibbell, J. 1991. Notes on Carmen: Carmen Miranda, seriously, Village Voice, October 29: 43-45.

Geoghegan, H. and Leyshon, C. 2012. On climate change and cultural geography: farming on the Lizard Peninsula, Cornwall, UK. Climatic Change, 113(1): 55-66.

Geoghegan, H. \& Woodyer, T. 2014. Cultural geography and enchantment: the affirmative constitution of geographical research, Journal of Cultural Geography, 31(2): 218-229.

Gillan, K and Pickerill, J. 2012. The difficult and hopeful ethics of research on and with social movements. Social Movement Studies: Journal of Social, Cultural and Political Protest, 11(2): 133-143.

Matthews, H. 2003. Coming of age for children's geographies. Children's Geographies, 1: 36.

Mountz, A., Bonds, A., Mansfield, B., Loyd, J., Hyndman, J., Walton-Roberts, M., Basu, R., Whitson, R., Hawkins, R., Hamilton, T. and Curran, W. 2015. For slow scholarship: A feminist politics of resistance through collective action in the neoliberal university. ACME: An International Journal for Critical Geographies, 14(4): 1235-1259.

Philo, C. 2016. 'Childhood is measured out by sounds and sights and smells, before the dark of reason grows': children's geographies at 12, Children's Geographies, 14(6): 623-640. 
Woodyer, T. 2008. The body as research tool: embodied practice and children's geographies, Children's Geographies, 6(4): 349-362.

Woodyer, T. 2012. Ludic Geographies: not merely child's play, Geography Compass, 6(6): 313-326.

Woodyer, T. \& Geoghegan, H. 2013. (Re)enchanting geography? The nature of being critical and the character of critique in human geography, Progress in Human Geography, 37(2): $195-214$. 